\title{
Prevalence of self-medication among university students in Baghdad: a cross-sectional study from Iraq
}

Rawa J.K. Al-Ameri, ${ }^{1}$ Husham J. Abd Al-Badri ${ }^{2}$ and Riyadh K. Lafta ${ }^{3}$

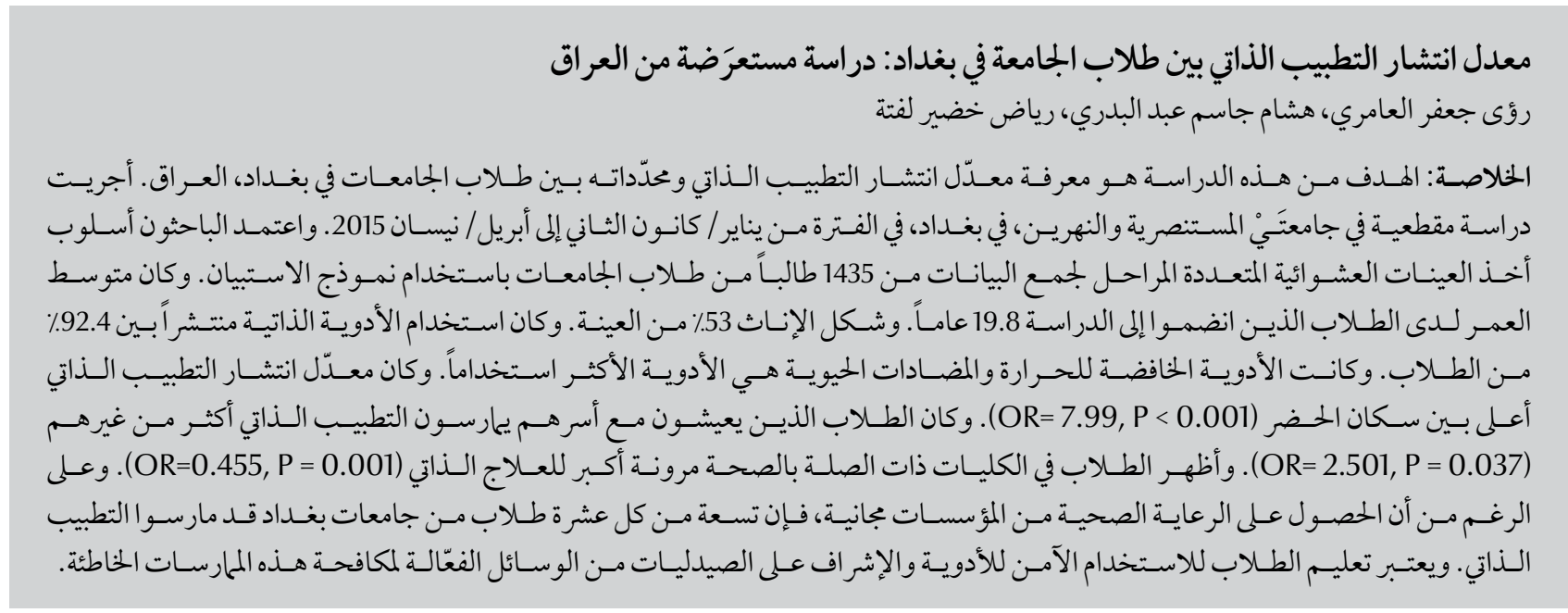

ABSTRACT The objective of this study is to find out the prevalence and determinants of self-medication among college students in Baghdad, Iraq. A cross-sectional survey was conducted in Al-Mustansiriyah and Al-Nahrain universities, Baghdad, from January to April 2015. A multistage random sampling technique was adopted to collect data from 1435 college students using a questionnaire form. The mean age of the joining students was 19.8 years. Females form $53 \%$ of the sample. Self-medications use was prevalent among $92.4 \%$ of students. Antipyretics and antibiotics were the most used medicines. Self-medication was higher among urban residents $(\mathrm{OR}=7.99, \mathrm{P}$ $<0.001)$. Students living with their families practiced self-medication more than others $(\mathrm{OR}=2.501, \mathrm{P}=0.037)$. Students at health-related colleges showed greater resilience to self-medication $(\mathrm{OR}=0.455, \mathrm{P}=0.001)$. Despite free access to healthcare institutions, nine out of ten college students from Baghdad universities have practiced self-medication. Education of students about the safe use of medications and supervision of pharmacies are effective ways to control this malpractice.

\section{Prévalence de l'automédication parmi les étudiants à l'Université de Bagdad : étude transversale iraquienne}

RÉSUMÉ La présente étude a pour objectif d'estimer la prévalence de l'automédication et d'en identifier les déterminants parmi les étudiants à I'Université de Bagdad (Iraq). Une étude transversale a été menée dans les universités d'AlMustansiriyah et d'Al-Nahrain à Bagdad, entre janvier et avril 2015. Une technique d'échantillonnage aléatoire à plusieurs degrés a été adoptée afin de collecter les données auprès de 1435 étudiants à l'aide d'une questionnaire. L'âge moyen des étudiants ayant participé à l'étude était de 19,8 ans, et 53 \% étaient des femmes dans l'échantillon. L'automédication était prévalente pour $92,4 \%$ des étudiants. Les médicaments les plus utilisés étaient les antipyrétiques et les antibiotiques. L'automédication était plus élevée parmi les citadins $(\mathrm{OR}=7,99, p<0,001)$. Les étudiants vivant encore chez leurs parents pratiquaient davantage l'automédication que les autres $(\mathrm{OR}=2,501, p=0,037)$. Les étudiants qui suivaient des études dans le domaine de la santé avaient moins tendance à recourir à l'automédication $(\mathrm{OR}=0,455, p=0,001)$. Malgré un accès libre aux établissements de soins de santé, neuf étudiants sur dix des universités de Bagdad avaient déjà pratiqué l'automédication. Éduquer les étudiants à une consommation sans risque des médicaments et mettre en place une surveillance des pharmacies constituent des moyens efficaces pour remédier à cette mauvaise pratique.

${ }^{7}$ Al-Dora Health-Care Centre for Family Medicine, Al-Karkh Health Directorate, Ministry of Health, Baghdad, Iraq. ${ }^{2}$ Noncommunicable Diseases Control Department, Public Health Directorate, Ministry of Health, Baghdad, Iraq (Correspondence to H.J. Abd Al-Badri: dr.husham82@gmail. com). ${ }^{3}$ College of Medicine, Al-Mustansiriyah University, Baghdad, Iraq.

Received: 9/3/2016; accepted:12/10/2016 


\section{Introduction}

Self-medication defined as patient use of medicines on his/her own initiative or according to advice from a pharmacist or a layperson instead of consulting a medical practitioner (1). Their use reported as being on the rise in the recent years especially among adolescents and young adults worldwide (2).This behaviour varies among countries, age groups, and between the sexes (3).

In the United States of America (USA) $75 \%$ of health problems are treated with non-prescription medicine (4): opioids are used by $13-18 \%$, followed by stimulants, including amphetamines (5\%), and sedatives (4\%) (5). Results from a 2005 study showed that $82 \%$ of women and $71 \%$ of men in the USA had used a self-medication drug in the previous 6 months (6). This was about twice their number of doctor visits or using a prescription medication (6). In 2008, the retail sales for selfmedication medicine approached US\$ 17 billion, rising to US\$ 26.5 billion in 2014 (7). About 36 million Americans use pain relief medications daily without professional health care advice (8). Around 16500 deaths and 103000 hospitalizations due to self-medication with non-steroidal anti-inflammatory medicines (NSAIDS) alone are reported each year in the USA (9).

Previous studies from the Middle East region revealed a high prevalence of self-medication by university students, ranging from $98 \%$ in a study from Palestine (10) to $55 \%$ in a study from Egypt (11). The students in this region used analgesics and herbals, often followed by vitamins and antibiotics, while opioids, stimulants and tranquilizers were used rarely (12-13). However, in a study carried out among university students in Jordan, antibiotics were the main self-medication used by $67.1 \%$ of the study sample (13).

In European countries, the greatest use of self-medication is found in the
United Kingdom and Germany, while Croatia and Greece rank as the least (14). A recent study from the United Kingdom (UK) and Ireland reported that stimulants were the most commonly used medicines (41.5\%) followed by vitamin supplements (29.2\%) (15).

Healthcare services in Iraq, including medication, is open and free; despite this, the practice of self-medication is prevalent.

To the best of our knowledge there have been few if any existing studies conducted in Iraq about self-medication use, especially among university students. The results of this study are important to build baseline data for Iraq.

The aim of this research was to discover the prevalence and determinants of self-medication practice among university students in Baghdad.

\section{Methods}

\section{Sample selection}

This cross-sectional survey was conducted during the period January-April 2015. A multistage random sampling technique was adopted by selecting 3 universities (Baghdad, Al-Mustansiriyah and Al-Nahrain) out of the main 5 in Baghdad. Colleges were selected from each university, according to the number of colleges in those universities, variety of available specialties and number of students. See Figure 1 for a schema showing the sampling process. Using stratified random sampling, 50\% of the students in the selected classes who were available at the time of the study and accepted to participate were invited to participate in this survey. Subclasses were considered the primary sampling units.

\section{Sample size (17)}

$\mathrm{N}=\left(\left[Z^{2} \times \mathrm{P} \times(1-\mathrm{P}) /(\mathrm{E})^{2}\right] \times\right.$ Deff $\times \operatorname{sex}$ estimate)/expected response rate

$$
\mathrm{N}=(384 \times 1.7 \times 2) / 0.8=1633
$$

Level of confidence measure ( $Z$ value): 1.96 (for $95 \%$ confidence level)

Margin of error: 0.05

Baseline levels of the indicators $(\mathrm{P})$ : 0.5

Design effect (Deff): 1.7 (16)

Expected response rate: 0.8

Number of sex estimates: 2

\section{Data weighting and adjustment}

Sometimes the sample proportion may differ between strata, thus data must be weighted to represent the population correctly. The overall students' number in the 3 selected universities was 58956 . The following formula was used for data weighting (17).

\section{$W i=\frac{1}{P 1 \mathrm{i} \times P 2 \mathrm{i} \times P 3 \mathrm{i} \times P 4 \mathrm{i} \times P 5 i \times P 6 i}$}

Wi is the raw weight for the data Pli is the probability of selection of the Universities, P2i for the colleges, P3i for the grades, P4i for the subclasses, P5i for the students and P6i for students' age proportion

\section{Questionnaire}

A semi structured questionnaire was developed to collect the relevant information pertaining to the study variables. In addition to information about age, sex, residence and academic grade, the questionnaire included the following questions in regard to self-medication.

- Have you ever used medications by yourself (non-professional prescription)?

- What are the medicines that you used?

- What was the purpose of taking these medicines?

- Did you experience adverse effects after taking these medications? Did these complications require professional medical intervention?

- Who advised you to take these medicines? 


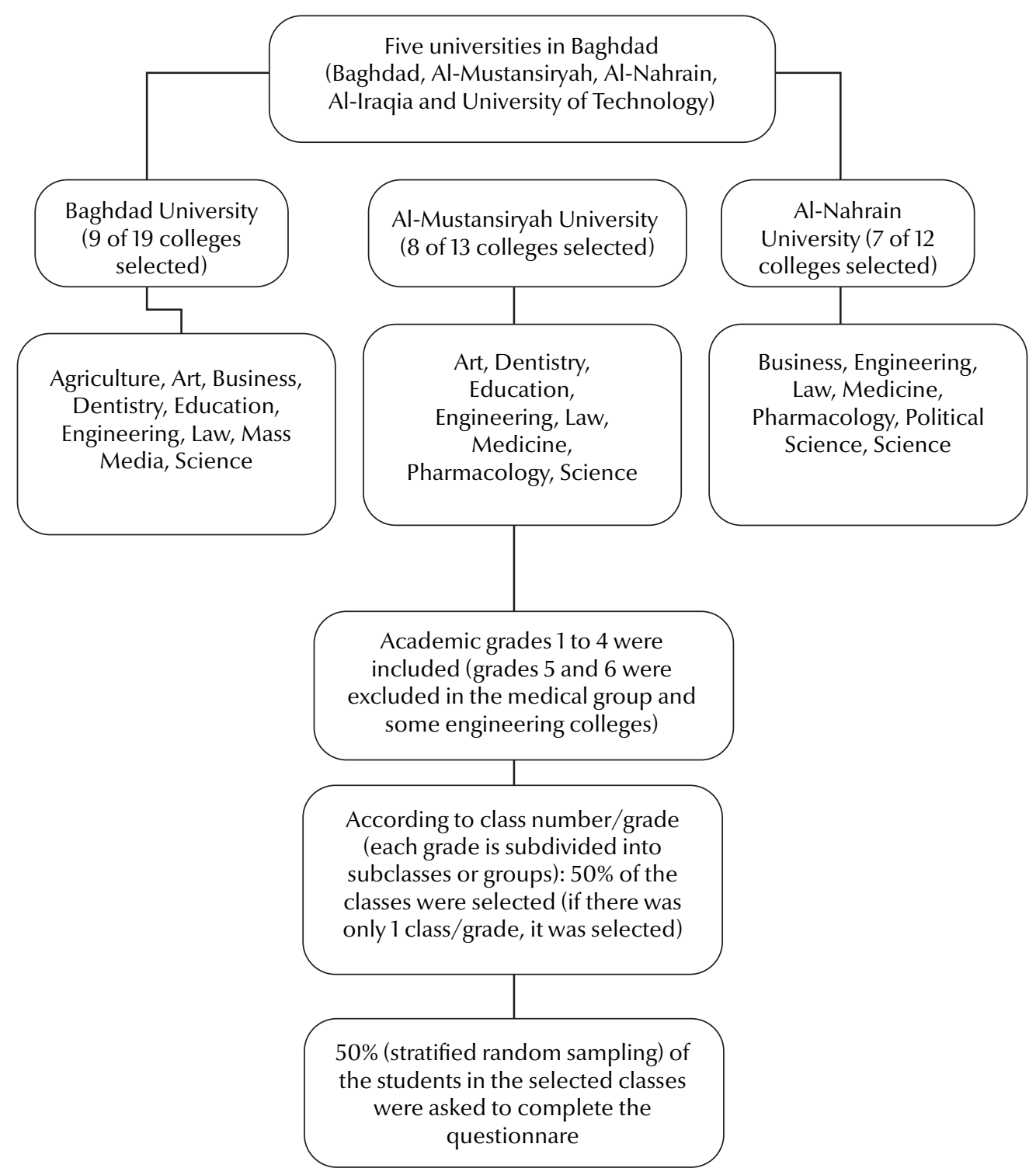

Figure 1 Flow-chart showing the sampling frame of the study (probability-proportional-to-size sampling)

- What was your source of information about the medicines?

- What were the reasons behind taking medicines without consulting a physician?

- What was your source for purchasing the medicines?

The questionnaire was revised by a scientific committee (community medicine consultants) for reliability and content validity. It was then piloted on a small sample of 30 college students from different universities to test the clarity and the applicability of the study tools, and to identify any difficulties that may be faced during data collection. The time needed for filling the questionnaire form by students was also estimated during this pilot study. Then, according to the results obtained, any necessary modifications were done. The pilot sample was not included in the study sample. The Kuder-Richardson formula 20 (KR-20) for internal reliability was 0.763 (18).

After obtaining official approval and task facilitating documents from the scientific committee of the Iraqi Counsel for Medical Specialization and approval from the ethics committee of the same council, the researchers contacted the Dean's office of each of the selected colleges to explain the objectives and rationale of the study and to get permission for data collection.

The students were met in the selected classes for about 15 minutes to explain and discuss the questionnaire items for more clarification before they were asked to complete the questionnaire. The questionnaire was anonymous to avoid causing any embarrassment to the respondents. Every student was given the complete unconditional choice to participate without 
any reward or penalty, and was assured that confidentiality of data throughout the study would be secured and that the data would not be used for purposes other than research.

They were asked to complete the questionnaire. This had been developed from several studies discussing a similar subject and was submitted to the committee in English. It was translated to the Arabic language for the purpose of simplification (and then retranslated into English for validation). Each completed questionnaire was considered as an informed consent for joining the study. The researcher visited each college twice during the day (08:3014:30). Data collection took about 10 weeks for the 3 selected universities. We distributed 1633 questionnaires; 1435 were completed giving a response rate of $87.9 \%$.

\section{Statistical analysis}

Each questionnaire was assigned a serial identification number. The data were analysed using SPSS, version 20. The data were presented as mean, standard deviation (SD), frequency and percentage. Sampling weights were used in the analysis.

The chi-squared test was performed to assess the statistical relations between defined dependent and independent variables. The independent $t$-test was used to test the mean age difference between users and non-users of selfmedication. Binary logistic regression was used to assess the adjusted odds ratio (OR) for association between the independent variables and self-medication; only significant variables found in the bivariate analysis were included in the model. $P$-value $<0.05$, was considered significant.

\section{Results}

More than a half the participants were females, 760 (53\%). The mean age was 19.8 (SD 1.6) years, range 18-24 years. The majority (91\%) were from urban areas (Table 1).

Out of 1435 college students included in the survey, $1326(92.4 \%$; $95 \%$ CI: 91.0-93.8) were practising selfmedication. The most commonly used medications were antipyretics (69.6\%), followed by antibiotics (46.1\%) and analgesics (40.1\%). Other types of medication used were: antitussives $26.9 \%$; anti-allergy medications $18.2 \%$; vitamins $17.4 \%$; herbal medicines $10.1 \%$; steroids $3.9 \%$ and hormones $2.8 \%$.

Medicines were used for headache relief by $71.1 \%$ of self-medicating students and $54.7 \%$ were treating influenza symptoms. Ten students (0.8\%) used

\begin{tabular}{|c|c|c|c|c|c|c|c|c|}
\hline \multirow[t]{2}{*}{ Characteristic } & \multirow{2}{*}{\multicolumn{2}{|c|}{ Overall }} & \multicolumn{4}{|c|}{ Self-medication } & \multirow[t]{2}{*}{$t$-test $(\mathbf{d f})$} & \multirow[t]{2}{*}{$P$-value } \\
\hline & & & \multicolumn{2}{|c|}{$\begin{array}{c}\text { Users } \\
(n=1326)\end{array}$} & \multicolumn{2}{|c|}{$\begin{array}{l}\text { Non-users } \\
(n=109)\end{array}$} & & \\
\hline \multirow[t]{2}{*}{ Mean (SD) age (years) } & \multicolumn{2}{|c|}{$19.8(1.6)$} & \multicolumn{2}{|c|}{$19.8(1.6)$} & \multicolumn{2}{|c|}{$19.1(1.1)$} & $3.701(1433)$ & $<0.001$ \\
\hline & No. & $\%$ & No. & $\%$ & No. & $\%$ & $\chi^{2}(\mathrm{df})$ & \\
\hline \multicolumn{9}{|l|}{ Sex } \\
\hline Male & 675 & 47 & 632 & 93.6 & 43 & 6.4 & $2.727(1)$ & 0.099 \\
\hline Female & 760 & 53 & 694 & 91.3 & 66 & 8.7 & & \\
\hline \multicolumn{9}{|l|}{ Residence } \\
\hline Urban & 1306 & 91 & 1228 & 94 & 78 & 6 & $54.548(1)$ & $<0.001$ \\
\hline Rural & 129 & 9 & 98 & 76 & 31 & 24 & & \\
\hline \multicolumn{9}{|l|}{ Accommodation } \\
\hline Family & 1202 & 83.8 & 1124 & 93.5 & 78 & 6.5 & $14.111(1)$ & $<0.001$ \\
\hline Not with family & 233 & 16.2 & 202 & 86.7 & 31 & 13.3 & & \\
\hline \multicolumn{9}{|l|}{ University } \\
\hline Baghdad & 537 & 37.4 & 497 & 92.6 & 40 & 7.4 & $3.034(2)$ & 0.219 \\
\hline Al-Mustansiriyah & 454 & 31.6 & 426 & 93.8 & 28 & 6.2 & & \\
\hline Al-Nahrain & 444 & 30.9 & 403 & 90.8 & 41 & 9.2 & & \\
\hline \multicolumn{9}{|l|}{ College } \\
\hline Health related & 256 & 17.8 & 219 & 85.5 & 37 & 14.5 & $20.875(1)$ & $<0.001$ \\
\hline Not health related & 1179 & 82.2 & 1107 & 93.9 & 72 & 6.1 & & \\
\hline \multicolumn{9}{|l|}{ Grade } \\
\hline 1st & 455 & 31.7 & 422 & 92.7 & 33 & 7.3 & $51.476(3)$ & $<0.001$ \\
\hline 2nd & 359 & 25 & 303 & 84.4 & 56 & 15.6 & & \\
\hline $3 r d$ & 301 & 21 & 287 & 95.3 & 14 & 4.7 & & \\
\hline 4th & 320 & 22.3 & 314 & 98.1 & 6 & 1.9 & & \\
\hline Total & 1435 & 100 & - & 92.4 & - & 7.6 & & \\
\hline
\end{tabular}

$P<0.01$ is statistically significant.

$S D=$ standard deviation. 
self-medication for insomnia and 8 $(0.6 \%)$ to relieve joint pain; a similar number used it for other types of pain.

Side-effects were reported by 206 (15.5\%) self-medicating students. These included allergy (27.7\%) and gastric upset (18.0\%). Others reported oedema, pallor, dry mouth, numbness, flushing and syncope. Out of the 206 who reported side-effects, 67 (32.5\%) reported they required medical intervention.

There were a number of reasons for self-medication. The vast majority of students (74.2\%) said that it was just for a trivial illness that does not need medical advice and $33.4 \%$ reported that they had experienced similar symptoms previously so they repeated the same medication. Other reasons cited were: easy accessibility $15.7 \%$; saving time $14.6 \%$; doctor's fees $10.9 \%$ and crowded clinics and the long waiting time $10.6 \%$.

The medications were bought from a pharmacy by 1232 (92.9\%) users. Other sources are detailed in Table 2.

The mean age of users was significantly higher than that of non-users (t-test $=3.701 ; \mathrm{P}<0.001)$. Sex and university of the students did not show any significant association with use of selfmedication. Students from urban areas practised self-medication more than students from rural areas, $94 \%$ vs $76 \%$ ( $c 2=54.548, \mathrm{P}<0.001)$. Prevalence of self-medications among students living with their families was significantly higher than those living away from the

\begin{tabular}{lrc}
\hline $\begin{array}{l}\text { Table } 2 \text { Source of medications among } \\
\text { Baghdad, } 2015\end{array}$ & students who used self-medication, \\
\hline Drug source & 1232 & $\%$ \\
Pharmacy & 48 & 92.9 \\
Home & 32 & 3.6 \\
Friends & 10 & 2.4 \\
Shops & 2 & 0.8 \\
Street & 2 & 0.2 \\
Health staff & 1326 & 0.2 \\
Total & & 100.0 \\
\hline
\end{tabular}

family, $93.5 \%$ vs $86.7 \%$ (c $2=14.111$, $\mathrm{P}<0.001$ ). Details of self-medication rates for other sociodemographic characteristics are shown in Table 1.

Logistic regression analysis was performed to identify the determinants of self-medication practice among the sample. Neither age of the students nor their academic grade had any real association with self-medication (Table 3). Urban residents were about 8 times more likely than rural residents to selfmedicate $(\mathrm{OR}=7.99, P<0.001)$. Students living with the family were 2 times more likely to practise self-medication than those living in other places $(\mathrm{OR}=$ $2.501, P=0.037)$.

\section{Discussion}

Self-medication is believed to do more harm than good and lead to wastage of resources, development of microbial resistance, adverse drug reactions, prolonged illness and drug dependence (19).

The prevalence of self-medication in this study was $92.4 \%$. Previous studies in the Middle East region showed comparable results. A study conducted in Oman revealed that $94 \%$ of 450 college students had practised self-medication (20). The prevalence of self-medication among 1260 university students was $90.6 \%$ in an Iranian study (21). Another Iranian study found that $80 \%$ of $300 \mathrm{col}-$ lege students were using medications without professional health advice (22). In a study from Saudi Arabia on 1596 students, $81.2 \%$ practised self-medication, especially during the exam period (12). In a 2007 study from Turkey among 418 volunteer students, $74.9 \%$ had practised self-medication (23) and in a 2012 study among 697 college students from Jordan, the prevalence of self-medication was $67.1 \%$ (13).

The most commonly used self-medications in our study were antipyretics and antibiotics to treat headache, flu

\begin{tabular}{lcccc}
\hline \multicolumn{4}{l}{ Table 3 Logistic regression analysis for the determinants of self-medication practice among university students in Baghdad } \\
\hline Characteristic & B & $P$-value & OR & $95 \% \mathrm{Cl}$ \\
Age & -0.243 & 0.383 & 0.785 & $0.455-1.354$ \\
Urban resident & 2.078 & $<0.001^{* *}$ & 7.990 & $3.366-18.965$ \\
Living with family & 0.917 & $0.037^{*}$ & 2.501 & $1.057-5.921$ \\
Health-related college & -0.787 & $0.001^{* *}$ & 0.455 & $0.288-0.718$ \\
Grade & 0.645 & 0.091 & 1.907 & $0.902-4.031$ \\
Constant & 4.111 & 0.377 & 61.008 & - \\
\hline
\end{tabular}

$B=$ coefficient of regression.

$O R=$ odds ratio.

$\mathrm{Cl}=$ confidence interval

*Significant at $<0.05,{ }^{* *}$ significant at $<0.01$. 
and fever. A study done in Saudi Arabia found that $80 \%$ of self-medication users were taking antipyretics and NSAIDs for headache and fever (12). In studies from Egypt (11), Turkey (14), Palestine (10) and Oman (21), antipyretics and analgesics were the most used selfmedications by students.

On our study $46.1 \%$ of the students reported self-medication with antibiotics. Similarly, $46.2 \%$ of university students in Oman gave a history of selfmedication with antibiotics (21). In a study from Pakistan, self-medication with antibiotics was reported by $47.6 \%$ of the students of 6 different universities of Karachi (24). Self-medication with antibiotics was also reported by $44.5 \%$ of university students ( $43.0 \%$ medical, $46.0 \%$ non-medical) from Benghazi, Libya (25).

A wide variety of medicines are available in pharmacies and stores, and they are easily accessed by the users without any medical consultation. There are no clear rules and control on the over-thecounter medications in the Middle East region, especially in Iraq.

The current study showed that $15.5 \%$ of the participants who reported using self-medication had suffered from side-effects. Similarly, a study conducted in Kuwait showed that $14.8 \%$ of 900 undergraduate medical students reported adverse effects. Self-medication caused side-effects among $28.9 \%$ of 90 students from Suez Canal University in a cross-sectional study carried out in Egypt (26). Amount of medication, frequency of dose as well as the difference in the sample size caused differences in the prevalence of side-effects.
Allergies to certain medicines and gastric upset were the main side-effects for the misused medicines. This was similar to the results from studies conducted in Saudi Arabia (12), Jordan (13), Pakistan (24) and the Islamic Republic of Iran (27)

The most common reason reported by the students that encouraged them to use self-medication was that their illness was trivial and was not worth medical intervention. This was also reported in a study carried out in Jordan among 679 university students (13). The same reason was reported in 2 studies from Pakistan (28,29).

The majority of students in the present study got medications from pharmacies or they found them stored in their home. This is similar to reports from previous studies in Saudi Arabia (12) Turkey (23) and Oman (21). That raises the questions about health authorities' supervision in these countries on drug dispensing through pharmacies. Most of the developed countries have strong supervision and put limits on drug dispensing from pharmacies and tie it to medical prescriptions (30).

Our results revealed no real association between self-medication practice and age, sex and grade. These findings were in concordance with studies from Palestine (10) and the Islamic Republic of Iran (31). However, a study from Kuwait showed that females practised self-medication significantly more often than males (mostly painkillers for relieving menstrual pain); significant differences were also found in that study for age and grade (32).

Self-medication was significantly more common among students living with their families. This might be due to the availability of medicines in the home and parental advice for particular medicines. This agrees with the findings of other studies from Saudi Arabia (12), Turkey (23), Palestine (10) and the Islamic Republic of Iran (22). In contrast, no such association was found in a study carried out among 1296 medical students in Belgrade (33). This difference between European countries and Middle East region might be due to the independence of young adults and students and the policy for drug dispensing in Europe.

Our study showed a significantly lower prevalence of self-medications use among students of health related colleges. This agreed with a study from Palestine (10), although a study from Ethiopia did not show a similar association (34). Students' medical practice and knowledge about are bad outcomes thought to be the cause.

Students living in the urban area showed a significantly higher association with self-medication. Availability of medicines in stores and the high number of pharmacies with increases in advertisement for new medicines might be the cause. This agreed with a study from Egypt (26).

Institutional education of students about the safe use of medications should be considered. Strict policies could be introduced to regulate the procurement of medications and prohibit their purchase without a prescription through urging pharmacists to dispense them under supervised regulations.

Funding: None.

Competing interests: None declared.

\section{References}

1. Guidelines for the regulatory assessment of medicinal products for use in self-medication. Geneva: World Health Organization; 2000 (http://apps.who.int/medicinedocs/en/d/ Jh1462e/6.html, accessed 29 January 2016).

2. Potnis PS. Ohio pharmacists' perceptions of over-the-counter drug advertising. Toledo: University of Toledo, Theses and Dissertations; 2012:406
3. Johnston LD, O'Malley PM, Bachman JG, Schulenberg JE, Miech RA. Monitoring the future: national survey results on drug use, 1975-2009. Volume II: college students and adults ages 19-50. Bethesda, Maryland: National Institute on Drug Abuse; 2010.

4. DeLorme DE, Huh J, Reid LN, An S. The state of public research on over-the-counter drug advertising. Int J Pharmaceutical and Healthcare Marketing. 2010;4(3):208-231. 
5. Young AM, Glover N, Havens JR. Nonmedical use of prescription medications among adolescents in the United States: a systematic review. J Adolesc Health. 2012;51(1):6-17.

6. Hong SH, Spadaro D, West D, and Tak SH. Patient valuation of pharmacist services for self care with OTC medications. J Clin Pharm Ther. 2005;30(3):193-9.

7. Aker J, Beck M, Travis S, and Harris J. Consumer navigation and selection behaviors for OTC products in a retail setting. Indianapolis, Indiana: The Consumer Healthcare Products Association; 2014.

8. Wilcox CM, Cryer B, Triadafilopoulos G. Patterns of use and public perception of over-the-counter pain relievers: focus on nonsteroidal antiinflammatory drugs. J Rheumato. 200532(11):2218-24. PMID:16265706

9. Gutema GB, Gadisa DA, Kidanemariam ZA, Berhe DF, Berhe AH. Self-medication practices among health sciences students: the case of Mekelle University. J Applied Pharm Sci. 2011;1(10):183-9.

10. Sawalha AF. A descriptive study of self-medication practices among Palestinian medical and nonmedical university students. Res Social Adm Pharm. 2008;4(2):164-72. PMID:18555969

11. El Ezz NFA, Ez-Elarab HS. Knowledge, attitude and practice of medical students towards self medication at Ain Shams University, Egypt. J Prev Med Hyg. 2011;52(4):196-200.

12. Almalak H, Albluwi Al, Alkhelb DA, Alsaleh HM, Khan TM, Hassali MA, et al. Students' attitude toward use of over the counter medicines during exams in Saudi Arabia. Saudi Pharm J. 2014;22(2):107-12. PMID:24648821

13. Suaifan GA, Shehadeh M, Darwish DA, Al-ljel H, Yousef AM, Darwish RM. A cross-sectional study on knowledge, attitude and behavior related to antibiotic use and resistance among medical and non-medical university students in Jordan. Afr J Pharm Pharmaco. 2012;6(10):763-70.

14. Niskanen MA selection of non-prescription medicines in Finland and other European countries [thesis]. Kuopio: School of Pharmacy, University of Eastern Finland; 2012.

15. Singh I, Bard I, Jackson J. Robust Resilience and substantial interest: a survey of pharmacological cognitive enhancement among university students in the UK and Ireland. PLOS ONE. 2014;9(10):e105969.

16. STEPwise survey for NCD, Section 2: preparing the sample. Geneva: World Health Organization; 2015 (http://www.who. int/chp/steps/Part2_Section2.pdf?ua=1, accessed 21 February 2017).

17. Yansaneh IS. Construction and use of sample weights. New York: United Nations Secretariat, Statistics Division; 2003 (http://unstats.un.org/unsd/demographic/meetings/egm/ Sampling_1203/docs/no_5.pdf, accessed 21 February 2017).

18. Kuder GF, Richardson MW. The theory of the estimation of test reliability. Psychometrika. 1937;2(3):151-60.

19. Pagane JA, Ross S, Yaw J, Polsky D. Self-medication and health insurance coverage in Mexico. Health Policy. 2006;75(2):1707 .
20. Al Flaiti M, Al Badi K, Hakami WO, and Khan S A. Evaluation of self-medication practices in acute diseases among university students in Oman. Journal of Acute Disease. 2014;3(3):249-52.

21. Rezahosseini O, Roohbakhsh A, Tavakolian V, Assar S. Drug abuse among university students of Rafsanjan, Iran. Iran J Psychiatry Behav Sci. 2014;8(2):81-5.

22. Amani F, Mohammadi S, Shaker A, and Shahbazzadegan. Study of arbitrary drug use among students in universities of Ardabil City in 2010. J Ardabil Univ Med Sci. 2011;11(3):201-7.

23. Tanriverdi G, Kaplan F, Atay S. Non-prescription medicine usage prevalence in college students receiving education in branch of medical sciences. Int J Caring Sci. 2010;3(1):22-8.

24. Shah SJ, Ahmad H, Rehan RB, Najeeb S, Mumtaz M, Jilani MH, et al. Self-medication with antibiotics among non-medical university students of Karachi: a cross-sectional study. BMC Pharmacol Toxicol. 2014;15(1):2-7. PMID:25534613

25. Ghaieth MF, Elhag SR, Hussien ME, Konozy EH. Antibiotics self-medication among medical and nonmedical students at two prominent Universities in Benghazi City, Libya. J Pharm Bioallied Sci. 2015;7(2):109-15.

26. Mostafa A, Hany A, Ayed E, Ali E, Fathy B, Khalil D, Soliman S, et al. Patterns of self-medication misuse among university students. Int J Healthcare Sci. 2014;2(2):180-6.

27. Abbasi-Ghahramanloo A, Fotouhi A, Zeraati H, Rahimi-Movaghar A. Prescription drugs, alcohol, and illicit substance use and their correlations among medical sciences students in Iran. Int J High Risk Behav Addict. 2015;4(1):e21945.

28. Shoaib MH, Yousuf RI, Anjum F, Saeed L, Ghayas S, Ali T, et al. Survey based study on the use of non-prescription. African J Pharmacy Pharmacology. 2013;7(38):2652-6.

29. Mumtaz Y, Jahangeer A, Mujtaba T, Adnan S. Self-medication among university students of Karachi. J Liaquat University Med Health Sci. 2011;10(3):102-5.

30. Yadav P, Smith R, Hanson K. Pharmaceuticals and the health sector. In: Smtih R, Hanson K, eds. Health systems in low- and middle-income countries: an economic and policy perspective. Oxford: Oxford University Press; 2012.

31. Sarahroodi S, Maleki-Jamshid A, Sawalha AF, Mikaili P, Safaeian L. Pattern of self-medication with analgesics among Iranian University students in central Iran. J Family Community Med. 2012;19(2):125-9.

32. Al-Hussaini M, Mustafa S, Ali S. Self-medication among undergraduate medical students in Kuwait with reference to the role of the pharmacist. J Res Pharm Pract. 2014;3(1):23-7.

33. Lukovic JA, Miletic V, Pekmezovic T, Trajkovic G, Ratkovic N, Aleksic D, et al, Self-medication practices and risk factors for self-medication among medical students in Belgrade, Serbia. Plos One. 2014;9(12):e114644. PMID:25503967

34. Abay SM, Amelo W. Assessment of self-medication practices among medical, pharmacy, and health science students in Gondar University, Ethiopia. J Young Pharm. 2010;JulSep;2(3):306-10. 